Wright State University

CORE Scholar

8-1-2000

\title{
Strain Variation with Sample Thickness in GaN Grown by Hydride Vapor Phase Epitaxy
}

\author{
D. C. Reynolds
}

David C. Look

Wright State University - Main Campus, david.look@wright.edu

B. Jogai

J. E. Hoelscher

R. E. Sherriff

See next page for additional authors

Follow this and additional works at: https://corescholar.libraries.wright.edu/physics

Part of the Physics Commons

\section{Repository Citation}

Reynolds, D. C., Look, D. C., Jogai, B., Hoelscher, J. E., Sherriff, R. E., \& Molnar, R. J. (2000). Strain Variation with Sample Thickness in GaN Grown by Hydride Vapor Phase Epitaxy. Journal of Applied Physics, 88 (3), 1460-1463.

https://corescholar.libraries.wright.edu/physics/142

This Article is brought to you for free and open access by the Physics at CORE Scholar. It has been accepted for inclusion in Physics Faculty Publications by an authorized administrator of CORE Scholar. For more information, please contact library-corescholar@wright.edu. 
Authors

D. C. Reynolds, David C. Look, B. Jogai, J. E. Hoelscher, R. E. Sherriff, and Richard J. Molnar 


\title{
Strain variation with sample thickness in GaN grown by hydride vapor phase epitaxy
}

D. C. Reynolds, D. C. Look, B. Jogai, and J. E. Hoelscher

Semiconductor Research Center, Wright State University, Dayton, Ohio 45435

\author{
R. E. Sherriff \\ Air Force Research Laboratory, Materials and Manufacturing Directorate, Wright Patterson AFB, \\ Ohio 45433
}

\author{
R. J. Molnar \\ Massachusetts Institute of Technology, Lincoln Laboratory, Lexington, Massachusetts 02173
}

(Received 13 January 2000; accepted for publication 3 May 2000)

\begin{abstract}
High quality GaN crystals can be grown on sapphire by hydride vapor phase epitaxy. The thermal expansion mismatch between sapphire and GaN produces strain in the GaN crystal as it is cooled from the growth temperature to room temperature. The strain is evidenced by shifts in the photoluminescence and reflectance line positions. By analyzing the surface strain as the crystal thickness is increased, the thickness required to obtain zero surface strain can be estimated. This structure might provide a lattice matched and thermally matched substrate for further epitaxial growth of GaN. (C) 2000 American Institute of Physics. [S0021-8979(00)06315-5]
\end{abstract}

\section{INTRODUCTION}

Substantial progress in growing high quality GaN by the hydride vapor phase epitaxy (HVPE) method has been achieved. ${ }^{1}$ High growth rates make the growth of thick layers practical. These thick layers have the potential to provide lattice matched and thermally matched substrates for further epitaxial growth of GaN. The currently investigated HVPE epilayers are grown on sapphire substrates. GaN crystallizes in the wurtzite structure and the epilayer films grow with the "cc" axis normal to the growth interface. Due to the thermal expansion mismatch between sapphire and GaN, cooling from growth temperature to room temperature strains the GaN layer. A number of authors have shown that this strain is clearly evidenced by shifts in the photoluminescence (PL), photoreflectance (PR), and reflectance (R) line positions. $^{2-10}$ It was shown in Ref. 9 that the energy of the free exciton associated with the top valence band $\left(E_{A}\right)$ varies linearly with the in-plane and axial components of the strain tensor.

In the present work, we report on the strain near the surface of GaN epilayers with varying thicknesses grown by HVPE on sapphire substrates. We extract the surface strain as a function of thickness from transition energies determined by PL and R measurements. Optical measurements are ideal for determining the surface strain since they only penetrate a small distance into the sample due to the large absorption coefficient. We estimate that the surface strain would be fully relaxed for a layer thickness near $75 \mu \mathrm{m}$, allowing for the possibility of further epitaxial growth on a lattice-matched substrate. Time resolved PL decay measurements on the samples showed that radiative lifetime increased as the sample thickness increased, verifying that the crystal quality improves with reduced strain.

\section{EXPERIMENTAL DETAILS}

The samples used in the experiment varied in thickness from 0.8 to $61 \mu \mathrm{m}$. They were grown on (0001) sapphire substrates by the HVPE process. This growth technique employs a chloride-transport HVPE vertical reactor, with a growth rate $\sim 21 \mu \mathrm{m} / \mathrm{h}$ at $1050{ }^{\circ} \mathrm{C}$, which results in unintentionally doped GaN. Electrical measurements are bulk measurements so the electrical properties near the interface will also be sensed for all the samples, regardless of thickness. In fact, it is known that HVPE GaN layers contain a thin ( 2000 ̊) highly conductive region near the $\mathrm{GaN} / \mathrm{Al}_{2} \mathrm{O}_{3}$ interface. ${ }^{11}$ By using a differential Hall-effect analysis, it could be shown that the room-temperature electron concentration near the surface of each sample varied from $3 \times 10^{18}$ to $5 \times 10^{16} \mathrm{~cm}^{-3}$ and the mobility varied from 100 to 860 $\mathrm{cm}^{2} / \mathrm{V} \mathrm{s}$ for the thinnest to the thickest sample.

All optical measurements were made with the sample immersed in liquid $\mathrm{He}$ at $2 \mathrm{~K}$. Excitation for time-integrated photoluminescence was provided by the $3250 \AA$ line of a HeCd laser. PL spectra were produced by a high resolution $4 \mathrm{~m}$ grating spectrometer equipped with an RCA C 31034A photomultiplier tube. Reflectance measurements were made on the same spectrometer system using a high pressure Xe arc lamp source. Time-resolved PL decay measurements were made with a Hamamatsu model C1587 synchroscan streak camera. The excitation source for time-resolved measurements was a frequency-tripled mode-locked Ti: sapphire laser producing pulses with a wavelength around $2750 \AA$ and a nominal pulse width below 1 ps. Although the streak camera is capable of $10 \mathrm{ps}$ resolution, trigger jitter and the narrow spectrometer bandwidth limited the effective temporal resolution to about $50 \mathrm{ps}$. 


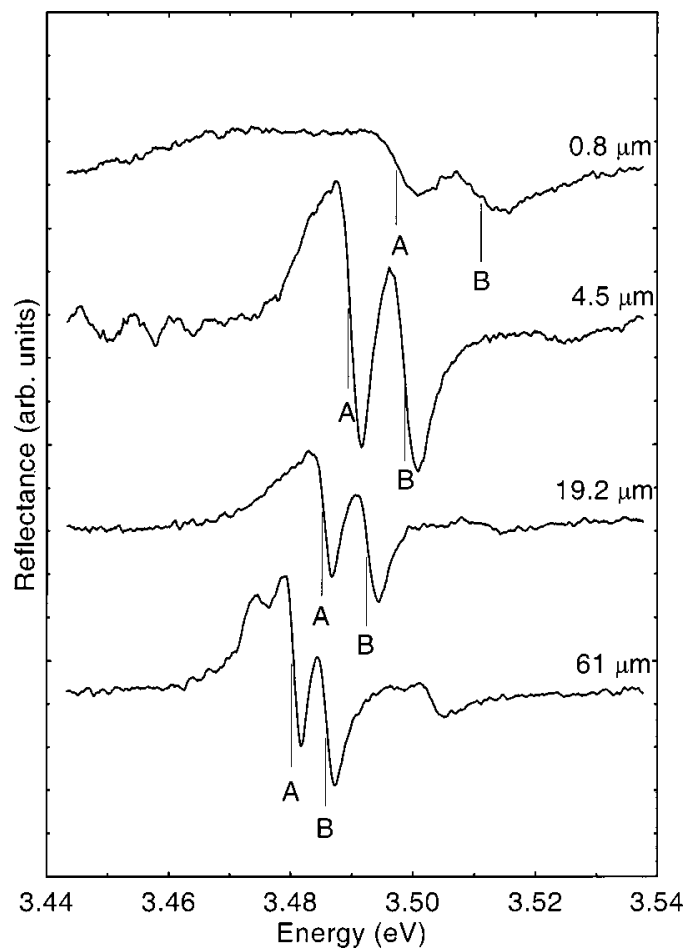

FIG. 1. Unnormalized reflectance spectra for four samples of HVPE GaN on sapphire. Each spectrum is labeled with the GaN epilayer thickness. The curves are shifted vertically for clarity. The estimated energies for the $A$ and $B$ free exciton transitions are indicated.

\section{EXPERIMENTAL RESULTS}

Unnormalized reflectance $(R)$ spectra for four samples with different GaN thickness are shown in Fig. 1. A linear tilt has been subtracted from each reflectance spectrum. Two Lorentzian-derivative line shapes are clearly visible for all four samples. These transitions are associated with the $A$ and $B$ free excitons, which involve the $\Gamma_{9}$ and $\Gamma_{7}$ valence bands, respectively. Additional features above and below the $A$ and $B$ exciton features make exact line shape fitting difficult, so the $A$ and $B$ transition energies are estimated using the midpoint of each line shape. PL spectra from the same four samples are displayed in Fig. 2. The PL spectra for the three thick samples have a similar shape, with a strong lowerenergy line from a neutral-donor-bound exciton $\left(D^{\circ}, X\right)$, and a smaller line at higher energy from the $A$ free exciton. For the thinnest sample, the $D^{\circ}, X$ line is significantly broadened and no free exciton is visible. The $B$ exciton is not visible in any of the PL spectra. A shift in all transition energies with sample thickness is evident in both PL and R spectra.

The strain-induced energy shift for the $A$ exciton was determined experimentally in Ref. 9 for GaN grown by metal organic chemical vapor deposition (MOCVD). They directly measured the $c$-axis lattice constant via x-ray diffraction at room temperature, and obtained transition energies using photoreflectance and PL at low temperature. The $A$-exciton energy was found to depend linearly on the $c$-axis component of the strain tensor, $\epsilon_{z z}$, according to $E_{A}=3.478$ $+15.4 \epsilon_{z z} \mathrm{eV}$. We use this relation to estimate $\epsilon_{z z}$ at the surface of each sample from the reflectance measurement of $E_{A}$.

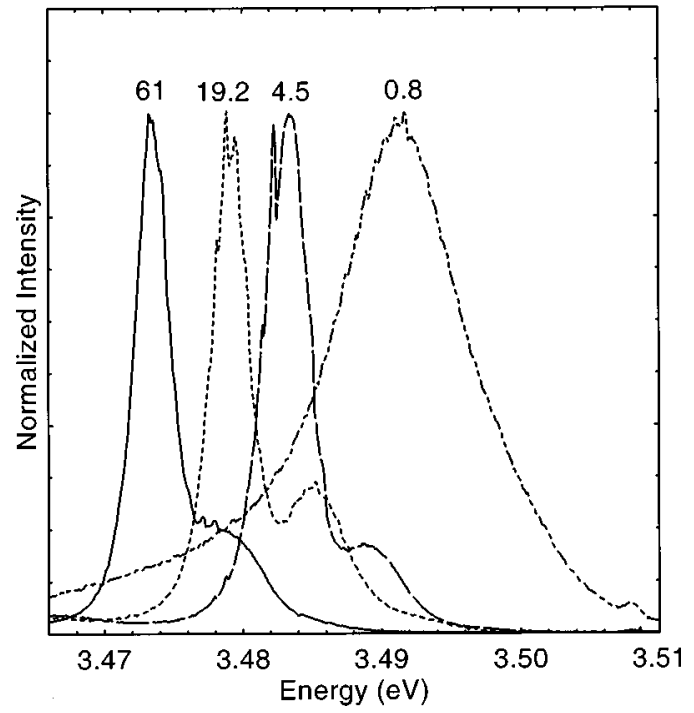

FIG. 2. Photoluminescence spectra for the same four samples in Fig. 1. Each spectrum is labeled with the GaN epilayer thickness in microns.

Figure 3 plots all the observed spectral features versus this extracted surface strain. The plot of the reflectance $E_{A}$ is, of course, exactly the strain calibration line: it is included to show the good agreement between the R and PL measurements of $E_{A}$. There are two observations worth noting. First, the separation between the $A$ and $B$ free excitons increases

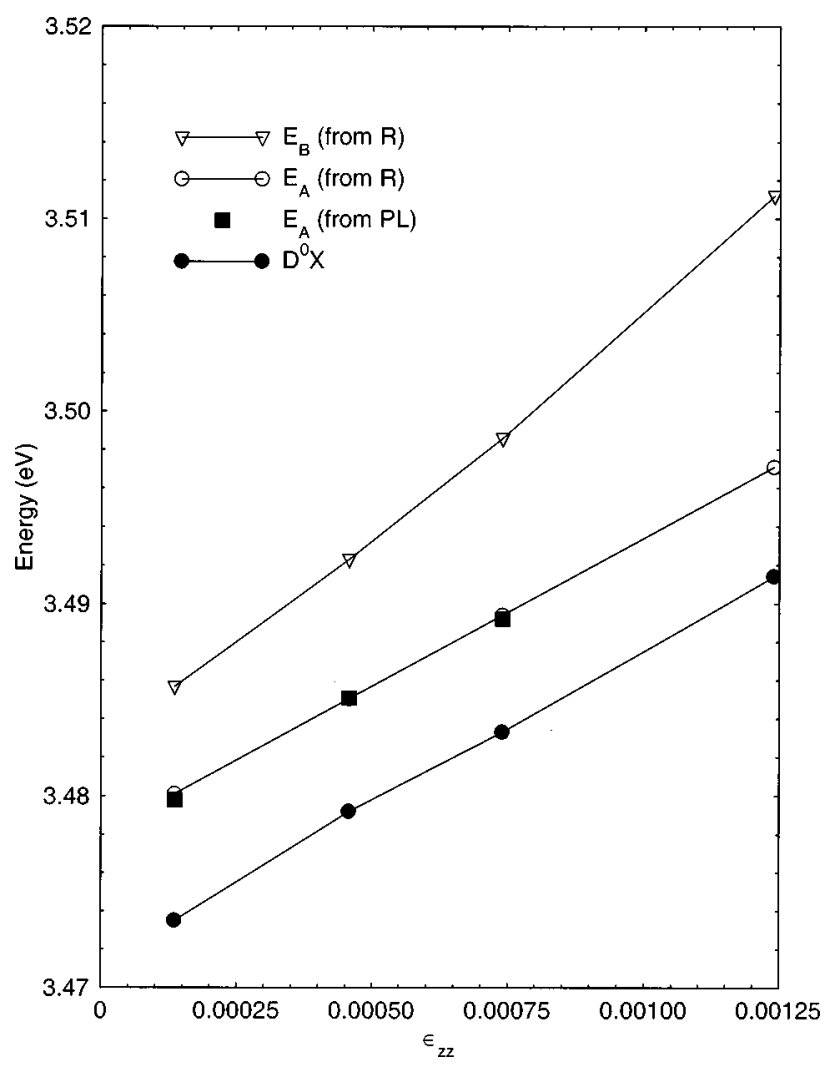

FIG. 3. The donor-bound exciton energy $\left(D^{\circ}, X\right)$, and the energies for the free excitons associated with the $A$ and $B$ bands plotted as functions of the extracted surface strain. Energies obtained from photoluminescence spectra are shown with solid symbols, while those obtained from reflectance spectra are shown with open symbols. 


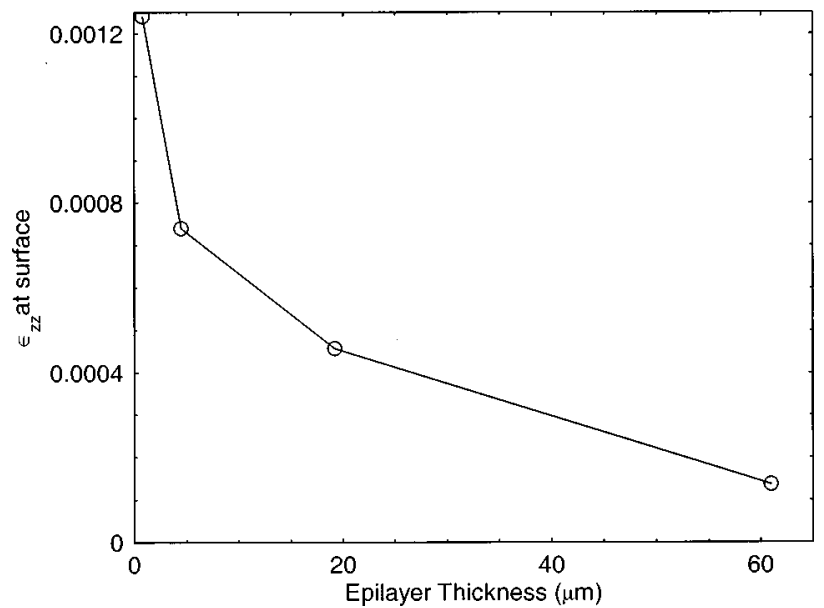

FIG. 4. The normal component of the surface strain as a function of GaN epilayer thickness.

with increasing strain in agreement with results on MOCVD grown GaN. ${ }^{9}$ Second, the separation between the $A$ free exciton and the $D^{\circ}, X$ transition is roughly constant for all four samples, implying that the binding energy of the exciton to the donor is constant with strain. Since, according to Haynes rule, ${ }^{12}$ the exciton is bound to the donor by some fraction of the binding energy of the donor, it follows that the binding energy of the donor does not change with strain. This is consistent with the observation in Ref. 9 that the binding energy of the $A$ exciton is not affected by strain.

The normal component of the surface strain, $\epsilon_{z z}$, is plotted as a function of epilayer thickness in Fig. 4. The surface strain relaxes rapidly in the early stages of layer growth and then more slowly as the layers thicken. Strain contributed from the lattice mismatch is believed to relax relatively early during growth with the formation of dislocations. Linear extrapolation of the strain curve suggests that a $75-\mu \mathrm{m}$-thick epilayer would have essentially zero strain. Separating this epilayer from the sapphire substrate would provide a lattice matched and thermally matched substrate for further epitaxial growth of GaN.

Time resolved PL measurements were made as an additional measure of crystal quality to correlate sample thickness with incorporated strain. The decay lifetimes are shown for both the $A$ free exciton and the $D^{\circ}, X$ transition in Fig. 5 as functions of strain. The decay data display single exponential decays for all of the transitions over several times the radiative recombination lifetime. Decay times were obtained from a least-squares fit of the data to a single exponential for intensities between 0.85 and 0.05 . The $D^{\circ}, X$ lifetime is greater than the free exciton lifetime as is usually observed. ${ }^{13-15}$ The lifetime increases with sample thickness, as the surface strain decreases. This suggests that the factors contributing to strain also introduce recombination paths as well as nonradiative decay processes. A slower exciton decay was also observed when the layer thickness was increased in MOCVD-grown GaN. ${ }^{16}$

\section{CONCLUSION}

Using photoluminescence and reflectance measurements, we have measured transition energies for the $A$ and $B$ free

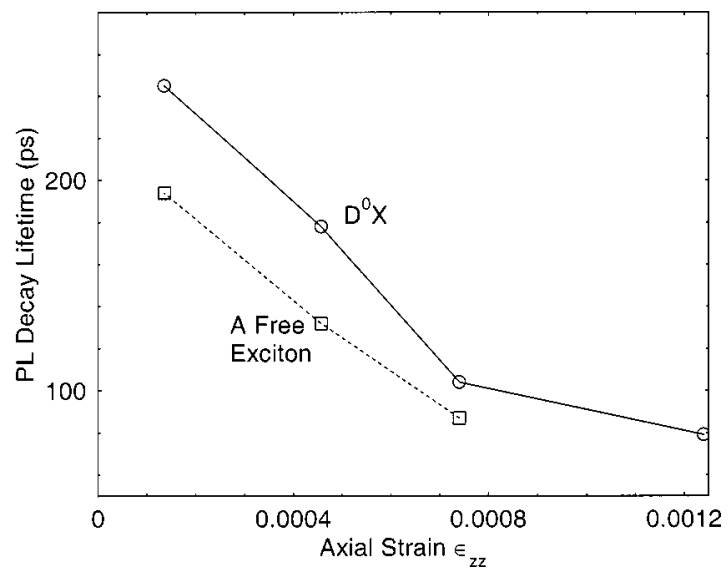

FIG. 5. Decay lifetimes of the A-band free exciton and the donor-bound exciton as a function of the axial strain $\epsilon_{z z}$.

exciton energies and a neutral-donor-bound exciton $\left(D^{\circ}, X\right)$ as a function of epilayer thickness for $\mathrm{GaN}$ layers grown by HVPE on sapphire. The separation between the $A$ and $B$ valence bands increased with strain, while the binding energy for the $D^{\circ}, X$ transition was roughly strain independent. The $A$ free exciton energy was used to estimate the surface strain, which decreased monotonically with increasing layer thickness. The thickness required to obtain zero surface strain is estimated to be about $75 \mu \mathrm{m}$. Such a layer might provide a lattice matched and thermally matched substrate for further epitaxial growth of GaN. Exciton lifetime measurements demonstrated that crystal quality near the sample surface improves as the strain is reduced.

\section{ACKNOWLEDGMENTS}

The authors would like to thank C. Huang for technical support, and J. Brown for sample thickness measurements. The work of D.C.R, D.C.L., B.J., and J.E.H. was performed at Wright Patterson Air Force Base under USAF Contract No. F33615-95-C-1619. This work was partially supported by the Air Force Office of Scientific Research (AFOSR).

${ }^{1}$ R. J. Molnar, W. Gotz, L. T. Romano, and N. M. Johnson, J. Cryst. Growth 178, 147 (1997).

${ }^{2}$ B. Monemar, J. P. Bergman, I. A. Buyanova, H. Amano, I. Akasaki, K. Hiramatsu, N. Sawaki, and T. Detchprohm, Topical Workshop on III-V Nitrides, Nagoya, Japan, Late News paper H-3.

${ }^{3}$ C. Merz, M. Kunzer, U. Kaufmann, I. Akasaki, and H. Amano, Semicond. Sci. Technol. 11, 712 (1996).

${ }^{4}$ J. Worton, D. E. Lacklison, A. V. Andrianov, T. S. Cheng, S. E. Hooper, C. T. Foxon, and L. C. Jenkins (unpublished).

${ }^{5}$ B. Gil, F. Hamdani, and H. Morcoc, Phys. Rev. B 54, 7678 (1996).

${ }^{6}$ S. Chichibu, A. Shikanai, T. Azuhata, T. Sota, A. Kuramata, K. Horino, and S. Nakamura, J. Appl. Phys. 81, 417 (1997).

${ }^{7}$ D. Volm, K. Oettinger, T. Streibl, D. Kovalev, M. Ben-Chorin, H. Diener, B. K. Meyer, J. Majewski, L. Eckey, A. Hoffmann, H. Amano, I. Akasaki, K. Hiramatsu, and T. Detchprohm, Phys. Rev. B 53, 16543 (1996).

${ }^{8}$ S. Chichibu, T. Azuhata, T. Sota, H. Amano, and I. Akasaki, Appl. Phys. Lett. 70, 2085 (1997).

${ }^{9}$ A. Shikanai, T. Azuhata, T. Sota, S. Chichibu, A. Kuramata, K. Horina, and S. Nakamura, J. Appl. Phys. 81, 417 (1997).

${ }^{10}$ J. W. Orton, Semicond. Sci. Technol. 11, 1026 (1996).

${ }^{11}$ D. C. Look and R. J. Molnar, Appl. Phys. Lett. 70, 3377 (1997).

${ }^{12}$ J. R. Haynes, Phys. Rev. Lett. 4, 361 (1960). 
${ }^{13}$ J. P. Bergman, P. O. Holtz, B. Monemar, M. Sun Da Ram, J. L. Merz, and A. C. Gossard, Phys. Rev. B 43, 4765 (1991).

${ }^{14}$ R. A. Mair, J. Li, S. K. Duan, J. Y. Lin, and H. X. Jiang, Appl. Phys. Lett. 74, 513 (1999).
${ }^{15}$ G. E. Bunea, W. D. Herzog, M. S. Unlu, B. B. Goldberg, and R. J. Molnar, Appl. Phys. Lett. 75, 838 (1999).

${ }^{16}$ P. Lefebvre, J. Allegre, and H. Mathieu, Mater. Sci. Eng., B 59, 307 (1999) 